\title{
La violencia simbólica en la escuela (1)
}

\author{
Marcelo R. Lobosco (2)
}

Resumen: La escuela como heredera de los Estados Nacionales ha practicado los ideales de libertad, fraternidad e igualdad, dando lugar a un proceso de igualación social y de pertenencia a un núcleo ético-mítico cultural común. Pero, el presente histórico en el que se instala la escuela actual no es Moderno sino Posmoderno o propio de una Modernidad tardía. La escuela de hoy afronta un desafío: o bien metaboliza los cambios del universo histórico-social de la realidad donde se constata el choque entre universos simbólicos, o bien realiza su práctica educativa sin tenerlos en cuenta. Para ello se postula en este trabajo la recuperación del sujeto a través de las subjetividades diferenciadas que intentan recuperar intereses, prácticas sociales, representaciones imaginarias a través de una dialéctica interna, considerando la pluralidad y diversidad de sentidos sociales, un sí mismo que resulte de la dialéctica de la conciencia y lo inconsciente por un lado y de la recuperación de las prácticas o intereses sociales por otro.

\section{LA ESCUELA EN LA MODERNIDAD}

En las páginas siguientes desarrollaremos la relación entre la escuela y la Modernidad. Más específicamente, trabajaremos la escuela como heredera y emergente de la formación histórico-social denominada "Moderna".

Así, la escuela como heredera de la Modernidad sostuvo los ideales de libertad, igualdad y fraternidad. El lenguaje de esta escuela es el lenguaje sintáctico, donde la representación del conocimiento y del proceso de enseñanza - aprendizaje por excelencia, se hace a partir de la sintaxis de los lenguajes naturales.

La escuela es Moderna, esto es, comprende al hombre como sujeto, fomentando un proyecto de autonomía que se sintetiza en el dictum kantiano: sapere aude, es decir, atrévete a pensar por ti mismo.

\section{LA ESCUELA Y LA FORMACION HISTÓRICO-SOCIAL ACTUAL}

La escuela de fin de siglo debe redefinir su rol en torno a la formación social del presente histórico.

La misma debe redefinir su función social, en torno a:

a) La consolidación y la construcción de la identidad local, nacional y latinoamericana.

b) El mantenimiento y la profundización del sistema democrático. 
c) La generación de crecientes niveles de justicia social transformadoras de la realidad.

d) La elevación de los índices de productividad del país.

Por su característica la escuela es el único lugar donde se distribuyen los conocimientos generados en el sistema científico-tecnológico.

La escuela de hoy afronta un desafío, o bien metaboliza los cambios del universo histórico-social de la realidad o bien realiza su práctica educativa, sin tener en cuenta a los mismos. Pero metabolizar el pasado es hacerse cargo de la crisis. Y ¿qué es lo que ha sucedido en un plano histórico-social?

1. La crisis del Estado de Bienestar (década de los 80`).

2. Crisis de las ideologías transformadoras de la realidad social.

3. Tecnificación del mundo de la vida.

4. Globalización de las comunicaciones.

5. Representación de la crisis de las ideologías, como fin de la historia.

6. Implosión de las economías nacionales y explosión planetaria de la economía neoliberal.

7. Globalización de la economía.

8. Escuela Moderna hija y heredera de los ideales de libertad, fraternidad e igualdad social.

9. Realidad Posmoderna, con vínculos lábiles, individualismos, privatizaciones de los proyectos colectivos, privilegios de los medios perceptivos-visuales-gestálticos frente a la lectura sintáctico-reflexiva.

En ese sentido tanto la CEPAL como la UNESCO han planteado como uno de los desafíos de la educación de fines de los 90 la articulación entre ciudadanía y competitividad. Es ahí donde aparece sobre la mesa la educación ética y ciudadana, como la necesidad de hacer frente a esta crisis ante la cual la escuela debe dar respuestas.

La educación de fin de siglo deberá vincular ciudadanía e integración social, ciudadanía y efectividad.

Tal como fue señalado por Samuel Huntington, se ha producido un alarmante desplazamiento de los conflictos del plano ideológico-político al plano cultural, es decir, al de las representaciones simbólicas. 
La guerra del Golfo, las luchas de Bosnia, la enemistad entre Paquistán y la India se han trasladado al plano del choque entre universos simbólicos.

Es por eso que la CEPAL denominaba a la industria cultural como 'topos articulador' entre dinámica cultural y dinámica productora.

Razones hay varias. Las mismas se fundan en el impacto que tiene la industria cultural en las relaciones sociales y el imaginario social.

Las identidades culturales se construyen a partir de mitos, registros comunes. Tradición, universos simbólicos construidos y legitimados socialmente, y prácticas sociales comunes.

Es en este contexto donde la industria cultural tiene un lugar paradigmático. Pues es en la industria cultural donde el mundo de la vida sedimenta los imaginarios y saberes subyacentes.

Es por esa razón que el informe Delors de la UNESCO, reclama que la Educación encierra un futuro donde la escuela ocupa un lugar emblemático.

Y en esta problemática se ubica la formación ética y ciudadana dando cuenta de un sujeto activo capaz de asimilar el cambio y de adaptarse y generar una transformación.

La sociedad actual requiere de sujetos activos. En ese sentido la formación ética y ciudadana deberá formar sujetos capaces de articular y manejarse con la incertidumbre.

Así, como afirma Cecilia Braslasky.

“(...) esto es [formar] seres humanos capaces de resolver problemas, que enfrenta cada uno de ellos y que enfrenta la sociedad en su conjunto".

Las competencias cognitivas o intelectuales derrotan operar con representaciones, símbolos, conceptos.

Dustchazky, citado por Braslasky, explicita tres tipos de habilidades:

I) Habilidades analíticas que implica operar con elementos.

II) Habilidades creativas. son aquellas vinculadas a la interpretación.

III) Habilidades metacognitivas: son aquellas que se refieren a la capacidad de reflexionar sobre el hacer.

Como afirmábamos antes, la formación ética y ciudadana se inserta en la escuela en la necesidad de formar ciudadanos con capacidad de resolver los problemas de 
la realidad. Formar a estos sujetos cuya identidad es una identidad narrativa, como afirma Ricoeur.

\section{ESCUELA MODERNA vs. REALIDAD POSMODERNA}

La escuela es Moderna, tal como venimos afirmando, comprende al hombre como sujeto. Este sujeto se instala en la sociedad civil a partir del pacto, es decir, del contrato jurídico-político. Por este último pasamos de la horda primitiva - o sea, estado de naturaleza - a la sociedad civil.

La escuela como heredera de los Estados Nacionales ha practicado los ideales de libertad, fraternidad e igualdad, dando lugar a un proceso de igualación social y de pertenencia a un núcleo ético-mítico cultural común. Pero, el presente histórico en el que se instala la escuela actual no es Moderno sino Posmoderno.

La sociedad Posmoderna se caracteriza por tener vínculos lábiles -como dijimos -, por la creciente fragmentación social, donde los proyectos colectivos se han privatizado y se han insertado en un proceso que tienen un término en común: globalización. En la era del vacío, bajo el imperio de lo efímero, en la era de los buenos negocios (business), donde estos son una de las certezas de la sociedad Posmoderna, nos encontramos con la globalización.

Dicho término pretende dar cuenta de la universalidad de la experiencia histórica. Si bien admitimos que en el plano de las comunicaciones acaece un proceso que ha atravesado profundamente las relaciones humanas, a su vez marcamos la diferencia de la unidad en la cual señalamos que la globalización no puede entenderse como uniformidad de la experiencia. Dado que toda experiencia es histórica, predicable de una formación histórico social peculiar, por lo tanto, no puede esperarse que la tecnificación del mundo de la vida implique universalidad sin tener en cuenta la multiplicidad. Por otra parte, la globalización muchas veces esconde y escinde la creciente marginalidad y exclusión social.

Es en este proceso donde se filtra por los poros de la escuela Moderna la violencia simbólica emergente de prácticas sociales excluyentes; pues toda práctica social -a pesar de ser vivida- emite sentidos que no siempre son tematizados por los educandos y por los educadores.

Así, la escuela es Moderna utiliza un lenguaje sintáctico en el que la representación del proceso de enseñanza-aprendizaje es mediatizado a través de los símbolos; entre ellos, las ideas de patria-nación-Estado. En tanto que la realidad históricosocial es Posmoderna, esto implica que el lenguaje es visual y gestáltico; hay una práctica de un lenguaje de la imagen (multimedia, videojuegos), el aprendizaje queda reducido a la inmediatez, con privatización de proyectos colectivos. La dialéctica de este proceso es: sólo a partir de una escuela Moderna que tematice y encodifique el universo socio-cultural Posmoderno, donde se pueda construir un nuevo pacto histórico-social en una dinámica de instituir una práctica social que no luche contra la violencia de una forma desplazada, sino construyendo un nuevo camino de pensar (Holzwege) que recupere la alteridad, es decir, a los otros, a los 
excluidos del sistema social en una resignificación de un nuevo "nosotros" no excluyente.

\section{EL REPLANTEO DE LA NOCION DE SUJETO}

Por lo anteriormente expuesto sabemos que estamos en este tiempo, de final de siglo, ante un replanteo, resignificación y cuestionamiento del sujeto Moderno.

Ya hemos anticipado, que la puesta en crisis de los grandes sistemas metafísicos, es decir la crisis de un sujeto racional, autocentrado, portador de la racionalidad histórico-social, introdujo la crisis del sujeto.

El discurso sobre el fin del sujeto pone en cuestión la posibilidad de fundamentar el origen, la posibilidad del conocimiento, en otros términos la filosofía teórica y por otra parte, de legitimar la lógica de la praxis el deber moral, el bien, es decir la filosofía práctica.

La Posmodernidad, o como nosotros preferimos denominar Modernidad tardía, pone en tela de juicio la noción de sujeto.

El término Posmodernidad surge, como debate teórico-cultural, de la arquitectura.

El sujeto moderno tuvo distintas figuras, ya sea como Estado, clase, pueblo o nación.

Ya no hay un "yo pienso" que debe poder acompañar a todas nuestras representaciones (Kant). Sabemos que el cogito (Descartes) no nos es traslúcido; por las impugnaciones del psicoanálisis de Freud, de la crítica de Nietzsche y de Marx, la filosofía de la sospecha, al decir de P. Ricouer.

La conciencia no es transparente ni traslúcida, pues hay cosas de las cuales no puede dar cuenta, por ejemplo la aparición de lo inconsciente.

Siguiendo el hilo de nuestra argumentación sobre las críticas, sobre las impugnaciones al sujeto, podemos mencionar las críticas al modelo fenomenológico dialéctico hegeliano. Las mismas fueron descriptas por C.Cullen:

1) Crítica del materialismo histórico: esta crítica impugna el concepto de experiencia hegeliano. No es el sujeto el que determina la realidad sino que son las condiciones económico-sociales, las que determinan al sujeto.

2) El positivismo lógico: criticó al sujeto constituyente afirmando que no hay intervención de un sujeto en el acto de conocer. No hay intencionalidad en la conciencia, hay hechos, datos, relaciones lógicas.

3) El existencialismo: critica al sujeto dialéctico hegeliano impugnándole su universalidad, punto de llegada de la experiencia de la conciencia como espíritu absoluto, proponiendo lo singular, la experiencia concreta. 
Asimismo, en este siglo, el filósofo francés J.P. Sartre criticó las posiciones egológicas de la conciencia en La trascendencia del ego (1936). Postulando una fenomenología que era deudora de su fundador E. Husserl, pero que planteaba diferencias.

Asimismo, el segundo Sartre, a partir - según nuestra interpretación -de un sincretismo epistemológico, criticó uno de los retoños de la modernidad: al marxismo (stalinista), criticándolo de tener una posición universalista apriorista, válido para todos los casos.

Por otra parte, Michel Foucault al final de su obra se opuso a una noción previa de sujeto, tal como lo exponían la fenomenología y el existencialismo. En un curso dictado en el Collège de France en 1982, explicita el concepto de sujeto como su búsqueda personal, pero vinculado al concepto de verdad.

Más claramente, en esta etapa de su pensamiento Foucault se preocupa por el cuidado de sí mismo, que según su perspectiva es más amplio que el "conócete a ti mismo".

En palabras del propio Foucault:

¿Bajo qué figura se han dado cita en la antigüedad occidental el sujeto y la verdad?. Existe un concepto central que permite absorber esta cuestión: el concepto de epimeleia / cura sui, que significa el cuidado de sí mismo. Esta cuestión del sujeto ha sido planteada hasta la actualidad de otra forma: bajo la fórmula del oráculo de Delfos: conócete a ti mismo".

Con lo anteriormente desarrollado podemos formularnos la siguiente pregunta: ¿qué lugar queda para el sujeto en la actualidad? ¿Cuál es el estatus epistemológico y ético-político?

Desde otro ángulo, Félix Guattari señala la importancia de los factores subjetivos en la historia social contemporánea. Por eso va a afirmar:

"De una manera general puede decirse que la historia contemporánea está siendo dominada cada vez más por un incremento de reivindicaciones de singularidad subjetiva: contiendas lingüísticas, reivindicaciones autonomistas, nacionales, que con total ambigüedad expresan una aspiración a la liberación nacional lo grupal o de género), pero por otro lado se manifiestan en lo que yo llamaría reterritorialidades conservadoras de la subjetividad".

Esta larga cita indica, según nuestra perspectiva, que no será justificada por sistema alguno, la aparición de lo que nosotros denominados subjetividad diferenciada. Es decir, movimientos de grupos sociales que a partir de la puesta en crisis de la noción de sujeto, se hacen cargo de intereses, prácticas sociales, imaginarios o núcleos ético-míticos que expresan la necesidad de dibujar y contornear esas pulsiones, imaginarios sociales y necesidades que quedaron fragmentadas. 
De allí, estas reterritorializaciones de la subjetividad que postula Guattari son para las que se encuentran expresadas en los movimientos ecologistas, los sin tierra en Brasil, o académicamente en la reflexión de la mujer sobre la problemática del género, o en el campo de las ciencias sociales, o normativas como el derecho, en el llamado derecho alternativo.

Por otra parte, con relación a la problemática de la modernización y la emergencia de las tradiciones en los países de Europa del Este, algunos de la ex Unión Soviética y otros de América Latina, Guattari afirma:

"Ante el actual estado de cosas, la sociología, las ciencias económicas, políticas y jurídicas parecen bastante mal pertrechadas para explicar semejante mezcla de arcaizante apego a las tradiciones culturales y, no obstante de aspiración a la modernidad tecnológica y científica, mezcla que caracteriza al cóctel subjetivo contemporáneo".

Y es que también - como señala Guattari - como se puede leer entre líneas, están las dificultades epistemológicas que tienen las ciencias en general y las sociales en particular, de encerrarse en el paradigma cientificista del neopositivismo postulando un paradigma alternativo cercano a lo estético- expresivo. Opinión ésta que sería interesante relevar y pensar, sin que esto suponga nuestra adhesión inmediata, ni nuestro rechazo irreflexivo y/o reduccionista.

También nos alienta Guattari a reflexionar sobre la importancia de la tecnología en el mundo globalizado contemporáneo:

"Las transformaciones tecnológicas nos obligan a tomar en cuenta a la vez una tendencia a la homogeneización universalizante y reduccionista de la subjetividad".

Nos quedamos con esta reflexión, porque aunque Guattari marca también los aspectos heterogéneos y singularizadores, nos parece relevante la primera parte de su afirmación, es decir aquella que señala a las tecnologías como productoras de subjetividades que tienden a generar representaciones universalizantes $y$ homogéneas de la realidad histórico- social.

Es oportuno en este lugar exponer lo que afirma Paul Virilo, en relación con las tecnologías, las percepciones y escorzos de la realidad telemática:

"Yo soy la máquina que les muestra el mundo, tal como yo lo veo (...) -escribía Vertov - el hombre de la cámara, esa que sumerge a los espectadores inertes en una forma sin precedentes de soledad".

Finalmente, postulamos con relación a la problemática del sujeto, la recuperación del mismo a través de las subjetividades diferenciadas que intentan recuperar intereses, prácticas sociales, representaciones imaginarias a través de una dialéctica interna, donde las opacidades de la conciencia, los símbolos, se presentan como tarea (Ricoeur) teniendo en cuenta la pluralidad y diversidad de sentidos sociales, quedando entonces un sí mismo que es resultado de la dialéctica de la ipseidad y 
de la mismidad, de la conciencia y lo inconsciente por un lado y de la recuperación de las prácticas o intereses sociales por otro.

Y en el plano moral un sujeto cuyo residuo tiene algo del yo que postula Taylor, que es condición de posibilidad de construir la identidad narrativa a través de un lenguaje evaluativo por medio del cual nos encontramos con los otros, y de un lenguaje interpelativo que intenta recuperar los intereses y prácticas fragmentarios, cuya validez queda limitada a los que comparten la tradición con hiperbien o bien supremo común y/o aquellos que han sido excluidos o marginados de la misma.

\section{Bibliografía}

BRASLAVSKY, Cecilia, Rehaciendo Escuelas: hacia un nuevo paradigma educativo en la educación latinoamericana, 1999.

Revista "Perspectivas", Unesco

CULLEN, Carlos, Reconocimiento y pluralismo. El lugar del otro en la formación del sujeto moral, Memorias del XIV Congreso Interamericano de Filosofía, Puebla, 1999.

FOUCAULT, Michel, La hermenéutica del sujeto. Curso en el Collège de France (1981-1982), México, Fondo de Cultura Económica, 2002.

GUATTARI, Félix; DELEUZE, Gilles. Rizoma. Introducción, Coyoacán, México, 1994.

GUATTARI, Félix. Las Tres Ecologías, Valencia, Pre-textos, 1996

RICOEUR, Paul, Sí mismo como otro, Madrid, Siglo XXI, 1996.

SARTRE, Jean Paul, La trascendencia del ego, [ En] Recherches philosophiques, Paris, 1936.

VIRILO, Paul, Estética de la desaparición, Barcelona, Anagrama, 1988.

.La máquina de visión, Madrid, Cátedra, 1989.

.La velocidad de la liberación, Buenos Aires, Manantial, 1995.

.Un paisaje de acontecimientos, Buenos Aires, Paidós, 1997.

.El cibermundo, la política de lo peor, Madrid, Cátedra, 1997.

. La bomba informática, Madrid, Cátedra, 1999.

TAYLOR, Charles, La ética de la autenticidad, Buenos Aires, Paidós, 1994. 
(1) Exposición para curso - taller en elVII Congreso Provincial y III Congreso Nacional de Políticas Educativas, La Pampa, 30 de septiembre, 1 y 2 octubre 1999.

(2) Profesor y Licenciado en Filosofía, Universidad de Buenos Aires, Diplome d' Etudes Approfondie de la Universite de Paris 8, Consultor de Unesco y Organización de Estados Iberoamericanos, Director ejecutivo de la Olimpíada Argentina de Filosofía, Profesor adjunto UBA, Profesor Asociado UNMDP, autor de Subjetividad y constitución del otro ( Almagesto), coautor de Tópicos de la razón práctica (Eudeba), La resignificación de la ética, la ciudadanía y los derechos humanos en el siglo XXI (Eudeba), Filosofía, educación y sociedad global (Unesco, El Signo), Phrónesis (Vicens Vives- Barcelona). Buenos Aires, Argentina. E-mail: marclob@uolsinectis.com.ar 